\title{
A MODEL FOR THE FORMATION OF STUDENTS' RESPONSIBLE ATTITUDES TOWARDS THE ENVIRONMENT FOR FUTURE PRIMARY SCHOOL TEACHERS
}

\author{
Muazzam Akmaljonovna Toshtemirova \\ Department Of Biology, Fergana State University, Uzbekistan
}

\section{ABSTRACT}

In this article, the model is described as "a system of elements that process certain aspects, connections, functions of the subject of research" by providing the most general description. The model presented in this article has been developed by analyzing the psychological, pedagogical, social, and philosophical literature on the problem under study, as well as recording experimental data. In designing the model, we relied on the rule that the experimental test work that the model should explain should be a schematic and idealized representation of the structure of the situation. As part of our model study, future primary school teaching can reflect the structure of preparation for the formation of perceptions about the use of nature in primary school students and the conditions we highlight.

KEYWORDS:- Model, experimental testing, psychological, pedagogical, rational use of nature, methodological training, motivational-valuable, cognitive, operational and reflexive training.

\section{INTRODUCTION}

The process of preparation consists of a system of interrelated stages of content, form and methods, deciding the specific goals and objectives of the work; the formative stage is a natural continuation of the learning process and has a complex content, form and methods of work; the process of completing assignments is accompanied by monitoring the progress of students, making adjustments to their work.

\section{Main body}

We will look in detail at the main structural components of the model we have developed, their interrelationships and their application. The preparation of students for the formation of ideas about the rational use of nature in primary school students is carried out for a specific purpose, which is a key component of the model. 


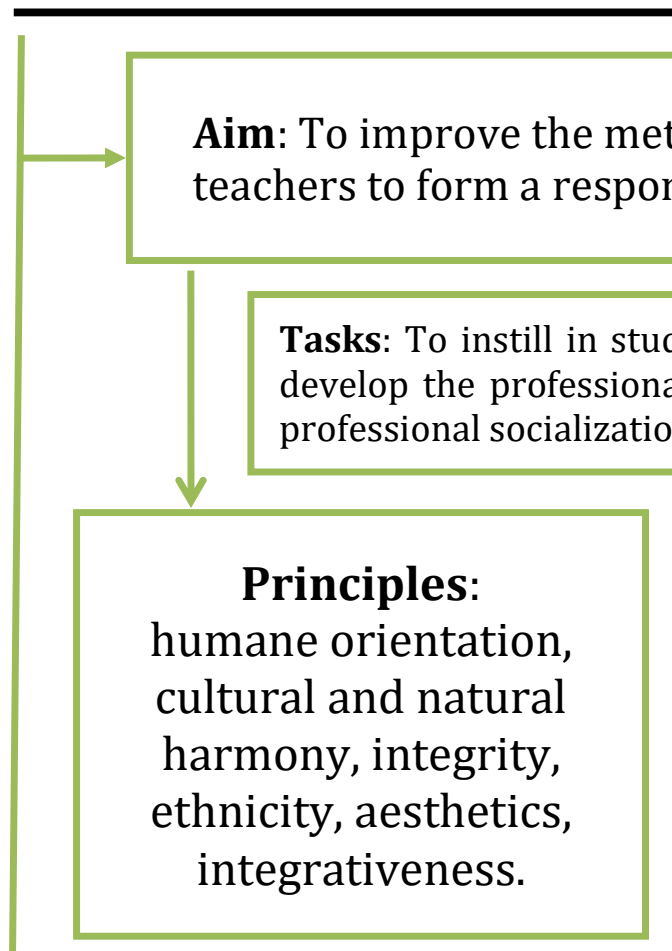

\section{The process of developing students' responsible attitudes towards the environment}

\begin{tabular}{|c|}
\hline \multicolumn{1}{|c|}{} \\
\hline Pedagogical \\
conditions: \\
creation of \\
favorable \\
pedagogical \\
conditions for a \\
person to \\
continuously \\
master the \\
development of \\
psychological and \\
pedagogical \\
influences, \\
\hline
\end{tabular}

Result: A future professional who develops a responsible attitude towards the environment in students

\section{Contents:}

It reflects the structure of teacher training in school students to form perceptions about the rational use of nature and the conditions we have highlighted. Preparation consists of a system of mutually consistent stages of content, form and methods, deciding the specific goals and objectives of the work; the formative stage is a natural continuation of the learning process and has a complex content, form and methods of work;

\section{Technology}

-Rely on significant aspects of their activities;

-creating a social environment for the development of a responsible attitude to the environment;

-Psychological and pedagogical integration of levels on the concepts of nature, environment, rational use.

\section{Forms:}

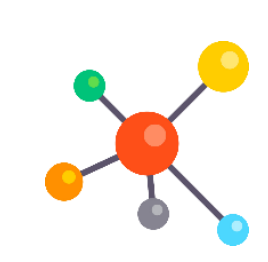

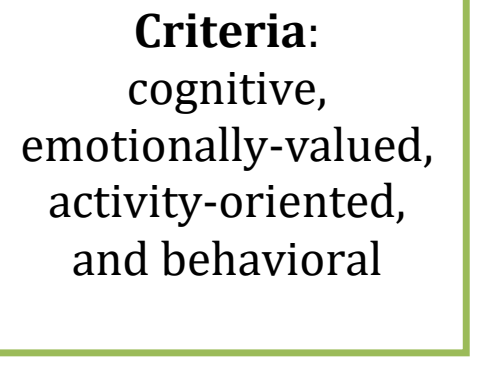

\section{Components:} motivationalvaluable, cognitive, operational and reflexive 
CURRENT RESEARCH JOURNAL OF PEDAGOGICS 2(10): 158-162,

October 2021 DOI: https://doi.org/10.37547/pedagogics-crjp-02-10-29

ISSN 2767-3278

(C)2021 Master Journals

\section{Crossref doi) 81 Google}

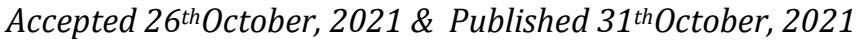

From our point of view, the most universal definition of the purpose of training in the context of this study is to prepare students to perform the functions of forming ideas about the rational use of nature in primary school students. The stated goal covers the entire period of the student's teaching.

The goal is defined by a number of tasks.

Examples of tasks to prepare a future primary school teacher to form perceptions about the rational use of nature in primary school students, in our view, could be:

- to give students a clear and unambiguous idea of the importance of rational use of nature;

- to foster students' conscious attitude to the implementation of the functions of the formation of ideas about the rational use of nature in primary school students;

-to form motivational-valuable, cognitive, operational and reflexive readiness of students;

-to organize work on the formation of ideas about the rational use of nature in primary school students

Corrections can be made to the specified tasks as a result of analytical activity of all participants of pedagogical process in preparation for them.

Results and Discussions: One of the most important components of the model for preparing a future primary school teacher to shape the rational use of nature in primary school students is, in our view, the study of students' level of preparation in order to obtain some information necessary for the training. The data obtained will be the basis for determining the content of teacher training to form perceptions about the use of nature in primary school students. It consists of four components: motivational-valued, cognitive, operational, and reflexive.

Theoretical study of this research problem, analysis of experience and experience of professional pedagogical activity helped to identify ways and conditions for the formation of professional training of future primary school teachers to form ideas about the rational use of nature in primary school students. By conditions, we mean opportunities, rules of operation, equipment, requirements, limitations in general. When applied to pedagogical education, the conditions are the constant factors that determine the course of the learning process and influence it. A systematic approach to research predetermines the development of conditions for the development of convenient, possible and necessary methods and techniques for improving the pedagogical process. A systematic view of the formation of professional training allows to describe the pedagogical conditions, and, as a result, to create a new didactic model, which provides a fundamentally new, optimal interaction between teacher and student.

The main factors determining the pedagogical conditions for the organization of the process of formation of vocational training were:

-a step-by-step approach to preparing students for the formation of ideas about the rational use of nature;

-continuity, consistency and coherence in preparing students for the formation of ideas about the rational use of nature, pedagogical cooperation, integration of theory and practice.

The existence of actions in accordance with the set goals and objectives, the gradual formation of knowledge, skills and abilities, the involvement of students in creative work - is a necessary condition for the effectiveness of the pedagogical process.

The successful solution of the multifaceted tasks of preparation can only be achieved in the fulfillment of a number of pedagogical requirements and conditions that determine the 
end result. In our opinion, The most effective approach to the study of the complex, complex problem of the formation of students' professional readiness to form ideas about the rational use of nature in primary school students, is the transition from the ultimate target system of educational activities to a system of professional knowledge, skills and competencies, defined by a common strategic direction aimed at the formation of a comprehensively developed harmoniously developed personality of each student.

The pedagogical conditions ensure the successful and effective conduct of the educational process, the development of the studied event, which is characterized by certain parameters aimed at developing the projected end result - the potential of the future primary school teacher. Finding and justifying effective ways to organize students' learning activities is a complex, laborintensive, and especially urgent task. It involves a set of issues related to the formation of motivation and interest in learning in learning: to establish a reasonably pedagogically justified dialogue of students at all stages of providing and mastering relevant educational information; combining individual, group and collective forms of teaching; activation of students' educational activity, development of their independence; organization of operational control and independent control of the results of educational and creative activities, if necessary, the organization of adjustments to the educational process; identify the most effective ways to develop students' creative abilities; organization of particularly effective interaction of teachers and students on the final results. Here the problem of quality of preparation of the future primary school teacher for work in fundamentally new conditions of professional activity remains especially acute.

According to V.A. Slastenin, the need to take into account the valuable and ethical components of the process of formation of training can allow a subject of education, which highly appreciates and understands the success of the acquisition of knowledge in science, to show great initiative in this area; acceptance of feedback from those around him in the group; accept the help of others to improve results; control and improve their communication style; search for new ways and means of mastering science; to feel the good or bad of those around him; show will and perseverance in the acquisition of knowledge, despite the difficulties that arise; emphasizes that they can demonstrate the ability to convince them of what the outcome and success of teaching depend on.

Conclusion: In the successful demonstration of initiative and effective pedagogical activity, all factors need to complement each other, their balance and interaction. In this case, the competence of the individual is manifested in accordance with his knowledge, skills and abilities, personal aspirations and interests, as well as the social conditions in which he develops.

Motivational-value training is the basis for successful acquisition of theoretical knowledge and practical skills by students. If the motivation of students to organize work on the formation of ideas about the rational use of nature in primary school students arises from the direct observation of science lessons during the internship, students will be more effective, they will analyze the quality of their preparation in nature with the help of teachers and classmates and practical skills will be applied in their future careers.

\section{REFERENCES}

1. To'raeva M.H. Ecology and life. - T .: Ibn Sina 
CURRENT RESEARCH JOURNAL OF PEDAGOGICS 2(10): 158-162,

October 2021 DOI: https://doi.org/10.37547/pedagogics-crjp-02-10-29

ISSN 2767-3278

(C)2021 Master Journals

Crossref do) 81 Google

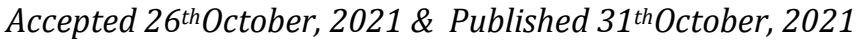

Publishing House. 1998. 37-p.

2. Nishonova N. Formation of ecological culture of general secondary school students (in the process of literary education).-T: 2001. -22 p.

3. Xabibullaev A.Sh. Some issues of nature protection / Problems of continuous ecological education and upbringing of the population. Part 1, - T: UZPFITI, 1993. 3-5-6.

4. D.Elmurodova. Preparing future primary school teachers for innovative professional activities. Dissertation for the degree of Doctor of Philosophy (PhD) in Pedagogical Sciences. T .: 2020

5. I.Uzakov "Pedagogical bases of formation of a sense of responsibility in primary school students :: Dissertation for the degree of Doctor of Philosophy (PhD) in Pedagogical Sciences..-T: 2008. -p 22

6. Ismatov I.Sh. Forming a responsible attitude to the environment in students: on the example of inorganic chemistry "// Dissertation for the degree of Doctor of Philosophy (PhD) in Pedagogical Sciences..-T: 2006. - p 22

7. .G'offorova, E.Shodmonov, G.Eshturdieva. Textbook / Textbook for 1st grade of General Secondary Schools. - T .: "Sharq" Publishing and Printing Joint-Stock Company, 2007. $128 \mathrm{p}$.

8. A.Bahromov Sh.Sharipov, M.Nabieva, Natural sciences. // Textbook for 4th grades of general secondary schools. T .: Editor-in-chief of Sharq Publishing and Printing Joint-Stock Company. http://eduportal.uz Tashkent 2020;

9. A.Bahromov, Sh. Sharipov, M. Nabieva, Natural Sciences. // Textbook for 3rd grades of general secondary schools. $\mathrm{T}$.: Cholpon Publishing House Tashkent - 2019 (Revised and supplemented sixth edition)
10. Abdullaeva K., Yusupova M., Raxmonbekova S. Etiquette Textbook for 2nd grade. - $\mathrm{T}$.: Mehnat, 2001. -96 p. 